\title{
TELEMEDICINE IN ELDERLY CARE DURING THE COVID-19 PANDEMIC: EXPERIENCE REPORT
}

\author{
Beatriz Oliveira Faria*1; Jhenifer Rodrigues Messias'; Lidiane Maria Garcia Silveira1; Carolina \\ Marques Ferreira1; Gustavo Garcia Pacheco'; Bianca Rodrigues Barbosa1 \\ and Layara Maria Garcia ${ }^{2}$
} ${ }^{1}$ Medical students at the University of Franca (UNIFRAN), Franca - SP - Brazil; ${ }^{2}$ Faculty Advisor of The Medicine Course at
Universidade Estadual de Minas Gerais (UEMG) and Universidade de Atenas (UniAtenas), Passos - MG - Brazil

\section{ARTICLE INFO}

Article History:

Received $10^{\text {th }}$ March, 2021

Received in revised form

$27^{\text {th }}$ April, 2021

Accepted $16^{\text {th }}$ May, 2021

Published online $30^{\text {th }}$ June, 2021

Key Words:

Elderly; Telemedicine;

Geriatrics; Students.

\begin{abstract}
Introduction: Telemedicine has been progressively applied and accepted, especially in the current context, the new Coronavirus pandemic, with an overload on the health system and the need for social isolation. Objective: To report the experience of global geriatric assessment practice by medical students through teleconsultations. Experience report: Teleconsultations were carried out by medical students in which instruments were applied for the global geriatric assessment of a 72-year-old woman from a short-term institution. Results: It was identified that the patient was independent to perform activities of daily living, however, she had uncontrolled blood pressure, depressed mood and demonstrated incredibility to the vaccination. The experience proved to be beneficial for students, due to the geriatric practice, and for the elderly woman, who received guidance to meet health demands and ensure her overall well-being. Conclusion: Telemedicine is a promising tool to ensure comprehensive care for elderly patients in a context of social isolation. Teleconsultations were important to highlight the advantages and obstacles of this type of care, which still requires overcoming complex structural problems for its effective application, such as the need for investment in equal access to quality internet and training of health professionals and the elderly in management of digital media.
\end{abstract}

Copyright (C) 2021, Tácito Almeida de Lucca et al. This is an open access article distributed under the Creative Commons Attribution License, which permits unrestricted use, distribution, and reproduction in any medium, provided the original work is properly cited.

Citation: Beatriz, Oliveira Faria; Jhenifer Rodrigues Messias; Lidiane Maria Garcia Silveira; Carolina Marques Ferreira; Gustavo Garcia Pacheco; Bianca Rodrigues Barbosa and Layara Maria Garcia, 2021. "Telemedicine in elderly care during the covid-19 pandemic: experience report", International Journal of Development Research, 11, (06), 48257-48260.

\section{INTRODUCTION}

Telemedicine is defined as the use of information and communication technologies in the health area, making it possible to provide services in this area in different situations, including when distance becomes an obstacle. This definition underwent changes over time, from a simple transfer of medical information to a complete offer of health care services, with the exchange of useful information for the diagnosis, treatment and prevention of diseases, in addition to the relevant function for research and education, with the purpose of providing a better quality of life for society ${ }^{1,2}$. Although the name "telemedicine" seems to be current, this term has been used for years, as historical records from the beginning of the 20th century demonstrate the performance of a remote transfer of an electrocardiogram by physician Willem Einthoven. In the 1920s, clinical applications of telemedicine were already carried out for patients on board or on islands, and in the 1950s, the transmission of radiographic images began in the $\mathrm{USA}^{1}$. Several factors have stimulated the development of this method of care, such as market growth, the incorporation of new technological developments, the growing acceptance of telemedicine, the overload of the health system and the population's interest in monitoring their health conditions. Brazil is the fifth largest country in the world and has one of the largest and most complete public health systems. However, there are great inequalities in the distribution of doctors in its territory, and while in the Southeast the density of doctors is 2.81 per thousand inhabitants, in the North and Northeast regions, this index drops to 1.4. Telemedicine then appears as an alternative to reduce such inequalities, enabling contact with communities in locations with difficult access and permanence, even with the difficulties of accessing the internet and electronic devices ${ }^{3,4}$. Even in a context where telemedicine was already present, the emergence of a new scenario speeds up the debate on its implementation: the new coronavirus pandemic. In search of measures to prevent the overload of the Unified Health System, together with the need for social isolation measures to prevent this pathology, telemedicine with consultations was authorized by Federal Law No. 13,989, of April 15, 2020. However, this measure was revoked due to contrary manifestations ${ }^{2}$. 
The most vulnerable population group in relation to COVID-19 are the elderly, especially those with chronic diseases. In Brazil, over the last 50 years, there has been a decline in the overall mortality rate, with a decrease in infant mortality and an increase in life expectancy. This process was described by Omran, in 1971, as an epidemiological transition, and there was an evolution from a profile of high mortality from infectious diseases to one in which deaths from chronic diseases predominated ${ }^{5}$. After the diagnosis of a chronic disease, the affected individuals start to have new tasks, with the need to get used to the loss of quality of life, characterized as incapacities, physical inconveniences, losses in social and financial relationships and in the preservation of hope. In this way, non-communicable chronic diseases are an important public health problem, in view of the overload they cause in the health system ${ }^{6}$. Even elderly people who do not have chronic diseases more often need various medical interventions and, in both contexts, the elderly population usually has complaints that can be minimized or even resolved through telemedicine, which can provide the elderly with health support. appropriately, allowing access to information related to their health, clinical monitoring and prophylaxis of pathologies ${ }^{4}$. This practice stood out in the period of social isolation due to the COVID-19 pandemic, a disease that causes greater complications in the elderly compared to the general population, an age group with a predominance of chronic diseases, which do not present an imminent risk of death. In this context of pandemic, telemedicine and epidemiological transition, the relevance of Telemedicine is highlighted, as a consultation method that enables effective care for the elderly, reducing the risk of infection by the new Coronavirus and limiting the burden on the health system ${ }^{2}$. Thus, the aim of the present study was to report an experience of the practice of a global assessment of the elderly by medical students through a geriatric teleconsultation.

\section{METHODS}

The Integration Program for Teaching and Family Health (PIESF) discipline of the Medicine course at the Universidade de Franca enabled students enrolled in the third year to provide care to elderly patients at a short-term institution in the city of Franca, interior of the state of São Paulo, in the year 2020. For the consultation, the BlackBoard digital platform was used in a practical activity during remote teaching due to the measures of social isolation. This experience took place in two moments, within a month between the first and second virtual meeting. This approach was possible due to the help of an employee of the institution in which the patient stayed during the days, who offered her own cell phone smartphone and ensured access to the platform. The students were divided into the functions of interviewing the patient, writing down information and guiding her. The approach used was the Global Elderly Assessment, with the help of the Google Forms platform for targeting and storing information. The students responsible for the care underwent training by the preceptor of the Elderly Health module, two weeks before the date of the first consultation, to prepare for the application of the global clinical geriatric assessment online.

To carry out the consultations, a questionnaire was created using the Google Forms application, containing a free and informed consent form and questions aimed at the global assessment of the patient's health. The institution's nurses and caregivers received via social networks a link to enter the virtual room. The questionnaire contained identification data and questions about self-reported anthropometric measurements, BP and blood glucose in the last measurement, food and nutrition, chronic diseases and pain, vaccination, medications in use, allergies, alcohol or tobacco use, history of surgeries or previous hospitalizations, history of falls, vision, hearing, cognition and mood, walking, urinary and fecal incontinence, psychosocial support, physical conditions in the residential environment, Katz Scale for functional assessment of basic activities of daily living, Lawton Scale for functional assessment of instrumental activities of daily life, Geriatric Depression Scale, leisure practices that bring pleasure to the patient and physical exercise. The patient accessed the platform through a cell phone assisted by the nurse in charge, the students who administered the teleconsultations accessed the platform through personal computers in their respective homes. The consultations were carried out in groups, while one of the participants was responsible for conducting the interview, two others recorded the information obtained in the questionnaire and the other members participated as observers. The collected data were discussed among the students in a virtual meeting after the first consultation and intervention proposals were elaborated to optimize the patient's quality of life.

Patient Data: Female, 72 years old, white, literate, Catholic and married. She has difficulty walking due to a fractured femur, requiring the aid of an orthosis. She lives alone, the sick husband is institutionalized and the daughter lives elsewhere. Patient reports that she has access to means of transport, but demonstrates difficulties in accessing services such as pharmacy and supermarket due to the distance. She is a housewife and does not receive financial benefits, such as Bolsa Família or social security assistance from the INSS, she receives financial subsidies from her daughter. She does not practice physical activities, just stretching in the morning, for about 10 minutes. She received visits from friends and family regularly, but this contact was hampered by the new Coronavirus pandemic. She reports adequate eating habits, with a wide variety of foods, regularly eating fruits and vegetables and denies smoking and drinking. She uses some medications: atenolol, hydrochlorothiazide, dipyrone and risperidone, but she does not know how to inform the dosage. She reports previous diagnoses of anemia, high blood pressure, gastritis, diabetes mellitus and depression. She underwent two orthopedic surgeries due to recurrent femoral fractures caused by falls. She demonstrates incredibility to vaccines, reporting that she does not remember when and what was the last vaccine taken, avoiding the vaccine update due to adverse reactions.

\section{RESULTS}

Patient evaluated in the last measurements with a blood pressure of $160 / 90 \mathrm{mmHg}$, weight of $64 \mathrm{~kg}$ and height of $1.55 \mathrm{~m}$, with a BMI of 26.39. With the help of daily life questionnaires, it was identified that a patient is independent to carry out their basic activities of daily living, such as bathing and dressing, as well as performing more complex activities, such as shopping, tidying up. home, use the phone and prepare your own meals. She presented a history of recurrent falls and fractures of the femur, requiring orthopedic surgeries, is being treated for hypertension, but uncontrolled, in addition, symptoms of lowering of mood were identified during the consultations, even with previous diagnosis and treatment for depression bigger. Furthermore, the patient patient describes and lacks knowledge regarding the benefits of vaccination, requiring guidance regarding the validity and importance of this practice. From the data collected, it was possible to establish an approach to the situation. Training, physical diet, mental health, practices to avoid falls and clarifications on the benefits of vaccination were carried out. The dietary approach involves the recommendation of a healthy and varied diet, focusing on the need to reduce sodium consumption due to hypertension. Regarding physical activities, one patient was instructed to continue stretching in the morning and start physical therapy, due to mobility difficulties that prevent him from performing other forms of physical exercise.

To avoid possible falls and fractures, it was recommended to remove rugs and low furniture from the house, as well as the use of closed and non-slip shoes and the installation of support bars in the rooms, especially in the bathroom. To reverse the lowered mood, the research of religious practices, dialogues with friends and family, games and other activities that were reported as pleasurable by the patient were addressed. It was also important to emphasize the importance of vaccination and the need for it to prevent diseases, as well as the encouragement to update the vaccination calendar. This approach through telemedicine was beneficial both for students, who came into contact with geriatric practice in a context of remote education and social isolation, and for the elderly, who were guided who sought to meet their health needs and provide their global well- 
being. Through experience, the applicability of telemedicine in geriatrics was verified. However, there were also adversities, which need to be overcome for the development of telemedicine in Brazil. The difficulty of the elderly with electronic devices is highlighted, requiring the instruction of professionals to assist patients in teleconsultations. In addition, an internet connection is a challenge, as its distribution is uneven, being absent or of poor quality in various regions of the country, as well as it can harm the fluidity of the consultations, such as what happened in the experience, making it impossible to complete the contact in one day and the interview must be continued in another week. The doctor-patient relationship also showed losses, since, due to the impossibility of using a camera during a video call, it was not possible to see the elderly woman, having difficulty in forming bonds. Communication was also difficult for the patient, since the image generated on the cell phone screen is small and the uncertainty that the students were listening during an interview was noticeable. Thus, the quality of a greater and equal distribution of internet and quality electronic devices stands out, as well as the qualification of professionals to handle this type of care, which reduces the patient's stress generated by the impediments to access.

\section{DISCUSSION}

The increase in population life expectancy has brought to light numerous discussions around strategies for comprehensive health care for the elderly in a scenario of frequent need for medical interventions and greater demand for resources and professionals. The accelerated aging of the population in Brazil becomes a major challenge for the national health system, which seeks not only to prolong longevity, but also to promote greater quality of life, independence and autonomy for the geriatric population ${ }^{4}$. The SARSCoV-2 virus pandemic highlighted the urgency of developing comprehensive geriatric care strategies, since the elderly are considered a vulnerable population to develop severe forms of the disease due to the association between typical age-related senescent alterations and pathological senile alterations individual. Although the incidence of new coronavirus infection is higher in the adult population, lethality is higher in the geriatric age group. The elderly have multimorbidities, such as the evaluated patient who has a wide spectrum of chronic morbidities such as hypertension and diabetes mellitus, this factor is strongly related to the increase in lethality from the virus, in Brazil $69.3 \%$ of deaths occurred in individuals above 60 years and $64 \%$ of these elderly had at least one risk factor ${ }^{7}$. The new coronavirus pandemic brought the situation of need for social isolation and strong demand for material and human resources, leaving the health system in several locations on the brink of collapse and causing telemedicine to emerge as a strategy for the continuity of health care and preservation of social isolation. Telegeriatrics enables the use of valuable resources to preserve the health of the elderly, such as the screening of patients with suspected SARS-CoV-2 infection, avoiding unnecessary visits to health services, remote monitoring of the health conditions of patients positive for isolation, as well as allowing the continuity of monitoring of non-emergency chronic diseases, such as chronic gastritis and major depressive disorder presented by the patient, which could be postponed by social isolation and impair the elderly's quality of life ${ }^{2}$.

Social isolation caused a great impact on the mental health of the population, both for the emergence of psychiatric disorders and for the aggravation of pre-existing disorders, by inciting feelings of loneliness, sadness, boredom, impotence, irritability and concern related to the disease itself and to economic survival. Such disorders may reflect changes in appetite, sleep disorders, family conflicts and increased consumption of alcohol or other drugs. Elderly people are particularly vulnerable to emotional and behavioral changes generated by social isolation and functional losses. The patient interviewed had a previous diagnosis of major depressive disorder and showed depressed mood associated with social distancing from the family in the context of the pandemic, the discontinuity of practices that gave her comfort such as going to church and meeting with friends, and the difficulties, despite the fact that to be independent, to perform certain activities of daily living, such as cleaning the home and going to the market, caused by pain and mobility restriction due to a femur fracture. In this context, it is essential to maintain the monitoring of mental health of elderly patients, telegeriatrics becomes particularly important for the safe and continued segment of mental health, as the patient was instructed at the end of the consultations, in addition to facilitating the accessibility of elderly people with restrictions. mobility and functional dependence on health services ${ }^{8}$. Despite a promising strategy to optimize health care, telegeriatrics needs to overcome complex structural problems in order to be widely disseminated, such as the unequal distribution of internet access and quality electronic devices, and the training of health professionals and patients to manage the technologies involved in remote queries. During the teleconsultations applied, these structural problems could be experienced, the elderly woman demonstrated difficulties in accessing the digital platform, needing help from the institution's nurse, in addition to suffering from connection problems that made it impossible for her to activate the camera during the video call, generating a certain distancing and making it more difficult to establish a quality doctor-patient bond.Internet connection problems led to the early termination of the first appointment, causing the assessment to be resumed in a later appointment, affecting the fluidity of the interview and acting as a stressor for those involved, a factor that made it even more difficult to establish a medical relationship quality patient, something essential for the elderly's adherence to the proposed interventions?.

\section{CONCLUSION}

It is concluded that telemedicine is a very promising tool to ensure the maintenance of comprehensive care for the elderly in a context of social isolation. The experience lived through teleconsultations was of great importance to highlight the advantages and obstacles around this type of care which, despite being promising, demands the overcoming of several complex structural problems for its application in a broad and effective way, such as need for investment in equal access to quality internet and the need to train health professionals and the elderly in the management of digital media. In addition, it shows the importance of training professionals and students in the health area to provide quality medical care through the use of telemedicine and to circumvent the possible complications inherent to this methodology, thus avoiding damage to the fluidity of consultations, the formation of fragile doctor-patient bonds and ethical and confidentiality problems that could affect the quality of care. Practical experiences involving geriatric teleconsultations are essential to incite discussions related to its applicability and elaboration of proposals to solve its structural problems, enabling its effective use.

\section{REFERENCES}

Barbosa IR, Galvão MHR, Souza TAd, Gomes SM, Medeiros AdA, Lima KCd. Incidência e mortalidade por COVID-19 na população idosa brasileira e sua relação com indicadores contextuais: um estudo ecológico. Scielo. 2020 Outubro.

Batista MPP, Almeida MHMd. Reflexões sobre a teleconsulta como dispositivo de cuidado para acompanhamento de idosos em distanciamento social devido à pandemia COVID-19. Revista Kairós-Gerontologia. 2020; 23.

Brito BdO, Leitão LPC. Telemedicina no Brasil: Uma estratégia possível para o cuidado em saúde em. Saúde em Rede. 2020; 6.

Dias S.C.F., Mendonça M.P., Oliveira D.S., Silveira K.B., Silveira R.M.R., editors. TELEMEDICINA APLICADA AOS CUIDADOS DOS IDOSOS NO BRASIL. Anais do V Congresso Brasileiro de Eletromiografia e Cinesiologia e X Simpósio de Engenharia Biomédica; 2018. Santa Rita do Sapucaí, Brasil: Instituto Nacional de Telecomunicações INATEL; 2018.4 p. 
Hammerschmidt KSdA, Bonatelli LCS, Carvalho AAd. CAMINHO DA ESPERANÇA NAS RELAÇÕES ENVOLVENDO OS IDOSOS: OLHAR DA COMPLEXIDADE SOBRE PANDEMIA DA COVID-19. Scielo. 2020 Setembro.

Lima RC. Distanciamento e isolamento sociais pela Covid-19 no Brasil: impactos na saúde mental. Scielo. 2020 Julho.

Maldonado JMSdV, Marques AB, Cruz A. Telemedicina: desafios à sua difusão no Brasil. Scielo. 2016 Novembro.
Malta DC, Silva AGd, Cardoso LSdM, Andrade FMDd, Sá ACMGNd, Prates EJS, et al. Doenças Crônicas Não Transmissíveis na Revista Ciência \& Saúde Coletiva: um estudo bibliométrico. Scielo. 2020 Dezembro.

Simões SdM, Oliveira A, Santos MAD. TELEMEDICINA NA PANDEMIA COVID-19. Revista Interdisciplicar de Pesquisa e Inovação. 2020; 7. 